\title{
Theorizing Rural Transformation Through Bourdieuian Lenses: Trumping Dominant Models With Sustainable Indigenous Practices
}

\author{
Joseph Seyram Agbenyega* \\ Peninsula Campus, Monash University, Frankston, Australia
}

\begin{abstract}
Education for rural transformation requires a critical analysis and appraisal of policies and education programmes, and skills development that can lead to the creation of sustainable jobs for rural people. This paper will examine and analyze how inclusion or exclusion manifests for rural people, and will do so with Pierre Bourdieu's socio-critical theoretical framework that provides a three pronged (Habitus, Capital and Field), but unified approach that can be utilized to theorize education for rural transformation. Bourdieu draws our attention to three interactive ways of conceptualizing and understanding inclusion, exclusion, marginalization, disadvantage and transformation via:1) the objective, physical, outright rejection in community due to the ways individuals are positioned and named in that community (field); 2) overt or covert denial of social, economic and cultural goods (capital), and 3) the inside subjective world, the space of thought, mind, attitudes, idea and interiority, which Bourdieu referred to as habitus (Bourdieu, 1990, 1996, 1998 \& 1999). The paper provides a socio-critical framework for educators of how to work with rural people to enhance their living standards.
\end{abstract}

Keywords:Bourdieu, Communities, Education, Rural, Transformation

\section{Introduction}

This paper begins with two questions: What should be the purposes of education for rural transformation in our contemporary time? By what means can those purposes be achieved for all rural people? These are complex questions with policy, socio-political, economic, theoretical and pedagogical components. The purpose of education for rural transform should be to support rural people to develop the necessary skills, dispositions and capabilities necessary to respond effectively, and manage their social situations. Social situations in this context are related to all the conditions in which people operate daily. Therefore, education for rural transformation requires that educators develop a long-term

*Email: joseph.agbenyega@monash.edu.

ISSN: 2091-0118(Print)/2091-2560(Online)

(C) 2014 JER 
vision, imagination, reflection and courage in order to make a positive difference to the lives of people living in rural communities.

Throughout history, human beings have been concerned with various economic and developmental practices as the mechanism for driving human growth and happiness. In essence, various developmental practices have led to rapid economic, information technology, health and educational changes in the world within the last three decades (Gibson, Cahill, \& McKay, 2010). These changes have had dramatic negative impact on the physical and emotional health, and wellbeing of rural people in particular (Moore \& Skinner, 2010). Some writers argue that while the lives of many people have been transformed through the benefits derived from advances in economic growth in many countries, there is evidence of worsening or unacceptably high levels of problems in a "minority of children across all aspects of development, health and wellbeing, including mental health, physical health academic achievement, and social adjustment"(Kennedy, McLoughlin, Moore, Gavidia-Payne, \& Forster, 2011, p. 7).

The negative impact of rapid economic development and industrialization can be seen within most rural communities in ways contemporary families struggle with meagre resources to live, take care of their children and in general, life for rural people has become more demanding and challenging (Gibson et al., 2010). Policies from various governments and service systems are also having difficulty servicing families in rural communities and in particular, resources in rural communities are on the decline as a result of some multi-national corporate activities, for example, mining and logging in rural communities, which are leading to deforestation and environmental degradation. It appears that the term 'development' has outlived its relevance. It has become an obsolete and damaging concept in the ways it is being operationalized because development activities globally, have tendered to focus narrowly on industrialization and capitalism, neglecting sociocultural factors such as communal living from which humans have for many years, fulfilled their social, cultural and economic needs. To explain this further, communal living is about re-personalizing society unlike capitalism and rapid industrialization induced by the term 'development', which is increasingly about materialism rather than people. In addition, more and more people are becoming dissatisfied with isolated, individual-intensive consumption households (Kanter, 2005).

The notion of community arose out of the Utopian theory. According to Kanter (2005), the utopian concept of community idealizes social unity where all people irrespective of their status or location experience fulfillment of their needs and happiness in the present. Thus, a strong sense of community is about self-sufficiency for all its own needs without having to outsource as opposed to the obsolete concept of development where individual households in industrialized and urban communities tend to use and waste a lot of resources, leading to the creation of problems for people living in rural communities in particular. A sense of community can assist teachers, researchers, and policy makers to 
develop values such as being co-operative, respectful and caring human beings for rural people who often have been marginalized through the selfish, materialistic mind-set so prevalent in contemporary world.

A sense of community also focuses on transformation rather than on developmental change in the narrow sense as the way to reinvigorate the debate about what is important for meeting the needs of people in need, particularly those in rural communities to live fulfilling lives. From the transformative perspective, education has been viewed as the tool for attaining human consciousness, where individuals are empowered to draw on their collective imagination and creativity to improve their own lives (How, 2003). It is against this background that this paper calls for a paradigm shift in education for rural transformation to promote the critical thinking skills of school-aged children in rural communities "to enable them function effectively in today's world of complex and ethnically polarized nations" (Asimeng-Boahene, 2009, p. 59).

The purpose of this paper is to apply the socio-critical concepts of Pierre Bourdieu (habitus, field, and capital)to inform the conceptualization of education for rural transformation and the promotion of critical thinking skills of scholars working in the area of rural transformation in particular. First, I will conceptualize the link between education and rural transformation. Next, I will examine and analyze Bourdieu's three conceptual tools and then provide a link between those and education for rural transformation. Finally, I will offer directions for culturally conscientious education for rural transformation that is sustainable and inclusive.

\section{Conceptualizing Education and Rural Transformation as Critical Thinking Skills}

Our contemporary time is encountering dramatic changes in rural contexts in many countries, where citizens are witnessing continuous deterioration of their livelihoods as a result of increased urbanization that encroaches on their cultural and economic capital such as land and traditional values. The irony is that rural people cannot attain the expected levels of transformation demanded by world bodies, policy documents and institutions without educators supporting them to develop critical thinking skills (Freire, 1970/2000). According to Asimeng-Boahene (2009) critical thinking skills are necessary for transformation of any kind. For rural people to develop skills appropriate for transformation to occur, they must be capable of thinking critically about complex societal and global problems. The rural-urban connection instigates the need for critical engagement with issues of rural-urban influences and interdependence, so that policy makers and people living in rural communities can explore ways in which beliefs and knowledge systems, capital, dispositions, and other cultural and developmental elements may facilitate the understanding of rural transformation.

It can be argued that "teaching [people] to think critically (Boyer, 1990, p. 5) provides space for dialoguing with oneself, and with others. It follows from this that critical 
thinking through rural-urban dialectic is an important mind tool for enacting and realizing rural transformation. So what is critical thinking? Ennis (1987) is of the view that good thinking is critical thinking or thinking that is based on rigorous and reasonable reflective thinking that is focused on deciding what to believe or do. This requires asking hard questions, for example, is it a good thing to do by displacing people who live in rural communities from their farming land by replacing those with concrete multistorey mega shopping malls for the sake of opening up economic development for selected few? Critical thinking thus includes, "those personal dispositions, abilities and competences related to creativity, initiative, problem-solving, flexibility, adaptability, the taking and discharging of responsibility and knowing how to learn and relearn" (Ball, 1989, p. 10).

I will come back to these dispositions when I discuss Bourdieu's conceptual habitus. In my view, education for rural transformation in the socio-critical sense is a politically committed response to addressing the problems of development. Deductively, education for rural transformation in the socio-critical sense is politically committed, and aims to achieve emancipation and transformation of individuals and society through critical human action (Adorno \& Hokheimer, 1944/1997; Gibson et al., 2010). Moreover, it is concerned with the appropriate positioning of people who live in rural communities in the context of national and global shifts. In this way, socio-critical education is seen as a key instrument for driving and fulfilling the goals of rural transformation. From a socio-critical perspective, education for rural transformation is about human happiness, which must pay attention to the complexity of human personality, the complexity of human environment, the different philosophies of life, different educational theories and practices (Bieler \& Morton, 2004; Gottesman, 2010). It is when education for rural transformation is conceptualized along these domains that fighting poverty in terms of the special conditions and contexts in which people in rural communities are located can be successfully achieved (Seitz, 2004; Zibechi, 2010). In the next section, I discuss the conceptual tools of Bourdieu.

\section{Bourdieu's Conceptual Tools}

Research on education for transformation highlights the variability in how educators, policy makers and technocrats understand and enact new reform in rural communities (Deppeler, 2010; Gibson et al., 2010).Global discourses on education for rural transformation have focused most exclusively on institutional and technocratic knowledge, thereby neglecting indigenous knowledges of people who live in rural communities (Zibechi, 2010).But taking a social critical perspective, as we shall see in my analysis that follow, highlights the complex mechanisms and environments within which effective education for rural transformation can be enacted (see for example, Apple, 2004; Bourdieu, 1989; Harker \& May, 1993; Leonardo, 2004). Despite diverse conceptions of what constitutes education for rural transformation discourses, there seemed 
to be increasing agreement that effective education for rural transformation is that which integrates indigenous knowledges in order to reduce poverty among people who live in rural communities (Deppeler, 2010). This focus demands that we locate education for rural transformation in Bourdieu's concepts of habitus, capital and field. These three interactive concepts emphasize the importance of dialogue with indigenous knowing for developing and transforming relations of power (Freire, 1970/2000) needed for rural transformation to occur. People in rural communities come to new understandings through examining their own habituses, capital and fields, and it is this examination that leads to action that confronts existing dominant societal structures, institutional and technocratic knowledge. Paulo Freire and Bourdieu focused their writing and critique on how dominant practices continue to maintain the status quo in education systems, and often, subject marginalized people to further exclusion and poverty (Freire, 2008; Gottesman, 2010).

This paper draws attention to Pierre Bourdieu's ideas of habitus, capital and field as these are implicated in the concept of education for rural transformation.

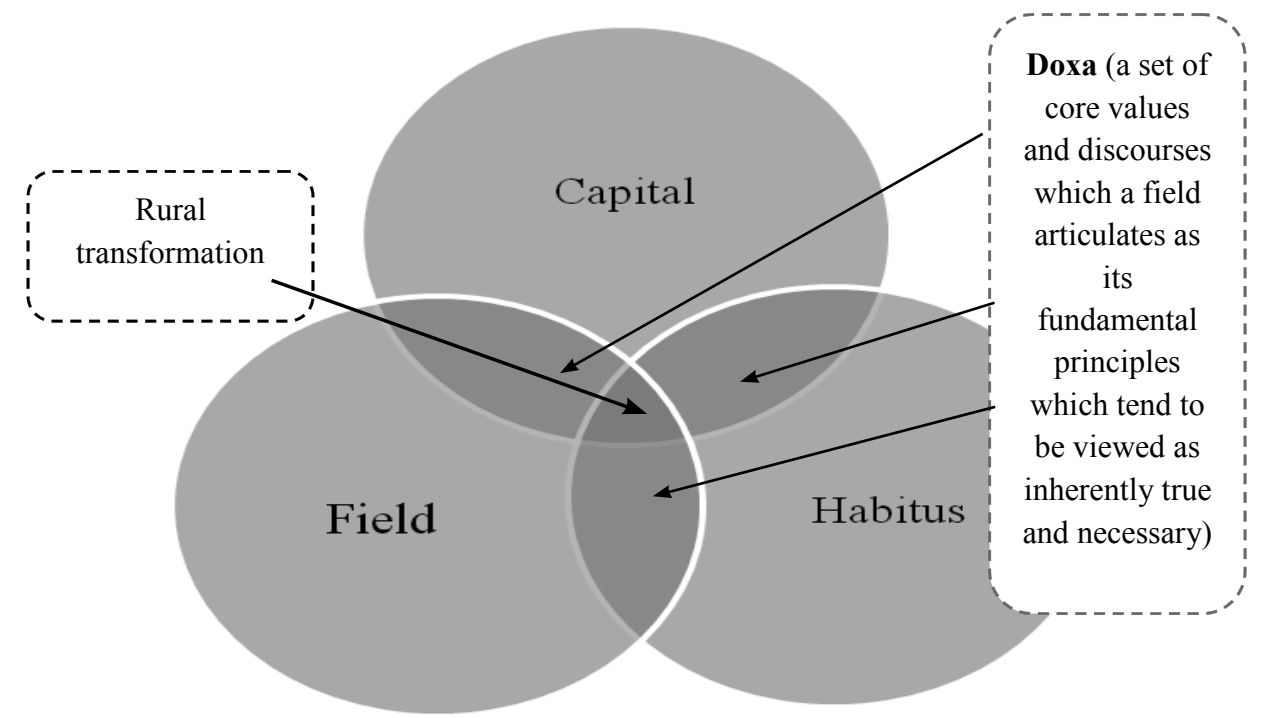

Figure1. A framework of interactive conceptual elements of education for rural transformation.

\section{Habitus and Rural Transformation}

Figure 1 shows the interrelationship among the three concepts of Bourdieu and the influence of doxa to produce practice. Bourdieu explains habitus as "internalized embodied social structures" (Bourdieu, 1989, p. 18) and "cultural unconscious or mental habits or internalized master dispositions" (Bourdieu, 1989, as cited in Houston, 2002, p. 157), which include beliefs, values, norms and attitudes. Dispositions of people living in rural communities inevitably reflect the social and cultural contexts in which they acquire them. 
This is the same for educators who facilitate education for rural transformation. Habitus influences the ways all people interpret and make sense of their world. Therefore, education for rural transformation in dialogue with indigenous knowing is one way educators can make sense of the 'rural field', needs and capabilities of people in rural communities. The mental structures and dispositions from which educators make choices of which approach to use in education for rural transformation, and how they utilize indigenous knowledge in this process are generated within the habitus. Habitus as embodied is visible through practice (Agbenyega, 2014). This means, the knowledge and skills the educator possesses become visible through how he or she approaches education for rural transformation. Therefore, the only way to determine whether an educator respects the rights of people living in rural communities, and takes their knowledge and contribution to education for rural transformation seriously is not in the ways the educator designs programs on paper but how the processes of program development and implementation for rural transformation are driven by people living in rural communities themselves.

On the one hand, perceiving people living in rural communities as simplistic citizens and as non-experts could lead to imposing predetermined structures on them which can humiliate their knowledge and experiences (Agbenyega, 2014). On the other hand, a positive image of people in rural communities would enable an educator to enact education for rural transformative practices that consider the strengths of people in rural communities, their cultural and symbolic capital in ways that add richness to sustainable rural transformation.

It is important to note that in education for rural transformation, educators activate their skills taking into consideration the agency of people in rural communities and enter into their social world of which they are both the product and agent (Bourdieu, 1989). They are products because institutional regulations (policies) and the transformative approach they utilise dictate how they implement their programs. They are also agents because they act on the transformative process with their knowledge. In many instances, an educator who is engaged in rural transformation practice may behave like 'fish in water', without feeling the weight of the water (Bourdieu, 1993). This means complacency on the part of educators can turn them away from taking a critical view on the approaches they adopt in implementing education for rural transformation. In this way, it can be argued that educators who are engaged in education for rural transformation become social and academic agents and advocates rather than an oppressive technocrat (Houston, 2002).

Past experiences and training may predispose an educator to think and act in particular ways. The habitus as a system of schemes of perception, appreciation and action, instead of remaining rigid, should be flexible and enable educators to perform acts of practical knowledge in education for rural transformation based on the identification and recognition of indigenous knowledge (Mills \& Gale, 2007).Educators must do so by generating appropriate strategies for education for rural transformation. This is important 
because rural transformation takes place in a "structured social world full of material and symbolic [capital such as financial resources], tools and language, structured social interactions such as rituals, and cultural institutions such as families and religions" (Tomasello, 2009, p. 207). People living in rural communities and their social institutions and family practices that educators want to transform are dynamic, fluid and shifting; hence, educators cannot restrict themselves to pre-programmed and rigid set of activities, rather they must be generative and transformative to answer complex rural problems.

Bourdieu sees habitus as potentially generating a wide collection of possible actions, at the same time enabling individuals to draw on transformative and constraining courses of action. He reasoned that:

Habitus is a kind of transforming machine that leads us to reproduce the social conditions of our own production, but in a relatively unpredictable way, in such a way that one cannot move simply and mechanically from knowledge of the conditions of production to knowledge of the products. (Bourdieu, 1993, p. 87)

In this way, "habitus is a structuring structure; that is, it is a structure that structures the social world. On the other hand, it is a structured structure; that is, it is a structure which is structured by the social world" (Ritzer, 1996, p. 541). To apply this sense to education for rural transformation implies that the composition of the educator's internalized dispositions determines the ways he or she selects education for rural transformation approaches. In doing education for rural transformation, we produce knowledge to structure people living in rural communities, which we are part of. We are in turn affected by the kinds of projects or education we implement in rural communities. In the section that follows, I explicate how capital is implicated in education for rural transformation.

\section{Forms of Capital and Rural Transformation}

Education for rural transformation involves the deployment of various forms of capital. According to Bourdieu, capital manifests in various forms including economic, cultural, social and symbolic (Bourdieu, 1998). Economic capital relates to wealth defined in monetary terms and determines the choice of the kind of technologies and resource deployment for use in a particular rural education. Cultural capital relates to a person's or institution's possession of recognized knowledge, which influences the transformation process in the rural field. Equally important is the social capital which is constituted by social ties, and symbolic capital, which is one's status, honour or prestige (Bourdieu, 1998). The nature and value of one's capital can determine the kinds of relationships entered into when working with people in rural communities. For example, an educator who considers his or her professional knowledge as superior to the cultural knowledge of people in rural communities could engage in practices that makes little or no reference to their cultural capital and habitus (Pihama, 1993; Slee, 2011). This calls for those concerned with education for rural transformation to consider the rights of members of rural communities. 
Acknowledging the capital that people in rural communities bring implies that they are recognized as the principal actors to be consulted and considered in writing policies and programs on education for rural transformation. It is thus necessary to take their perceptions and desires for an education that is meaningful to them to seriously form the basis for collective action towards transforming lives.

Economic, symbolic, cultural and social capital can contribute to education for rural transformation in many important ways, including influence on everyday relations and practice. Capital determines educators' agency, including those of the people in rural communities. Agency in this sense is the ability to strategically engage in and contribute to the processes of one's transformation (Webb, Schirato, \& Danaher, 2002). Many educators often attempt to involve people in rural communities in processes of change however may not value their knowledge capital (e.g. knowledge of their land, customs and traditions they have used through generations to conserve their ecosystem). Ignoring or devaluing the capital of people in rural communities may result in limited capacity of people in rural communities to strategically be involved in their transformative process. In this way, unless education for rural transformation considers the nature and extent of capital that both the educator and rural participants bring to the transformative field, the process of transforming their livelihoods can become a destabilizing experience for those for whom the program is intended. Bourdieu argues that the outcome of the struggle one engages in within an educational field is determined by the amount and nature of capital possessed by competing actors in that given field (Webb et al., 2002). This implies that the nature of the educator capital coupled with those of the people living in rural communities can turn education for rural transformation into a field of struggle.

Based on Bourdieu's ideas, it can be argued that the position the educator occupies in education for rural transformation is determined by hierarchy of the amount of knowledge and symbolic capital the individuals educator possess (Wacquant, 1998). This is also true of people living in rural communities for whom the education is intended. This means, there areal ways issues of social justice, human rights and equity when working in participatory education for rural transformation with people who are endowed with unequal amounts of cultural and economic capital (Bourdieu, 1998). The lack of recognition of a person's cultural capital therefore, may lead to the perpetuation of inequality and injustice against that person (Bourdieu, 1998; Mills \& Gale, 2007).

In addition, many educators often position people living in rural communities as deficits because they live in disadvantaged backgrounds and struggle to receive recognition and supplement their meagre cultural, symbolic and economic capital (Bourdieu, 1997; Mills $\&$ Gale, 2007). One of the key roles of educators in education for rural transformation is to accentuate various forms of capital people in rural communities possess, by assigning them important roles in rural transformation projects and not just treating them as objects of transformation. This means recognizing and authorizing the contributions of their 
knowledge through the development partnerships (Harker \& May, 1993; Leonardo, 2004). In this way, educators are helping to transform one form of capital to another form. For example, cultural knowledge of the land can be transformed into development knowledge, which in turn, be transformed into supporting improvements in status and lifestyles within rural communities (Bourdieu \& Passeron, 1990). Arguably, by focusing on how habitus and capital are implicated in education for rural transformation, educators can support people in rural communities to transform their lives without reproducing disadvantage (Webb et al., 2002). The next section will discuss the implications of field in education for rural transformation.

\section{Field and Rural Transformation}

Bourdieu uses field as a spatial metaphor to mean a network of relations among the objective positions. This conception of field is different from positivist conceptions of field as social location, for example, social milieu, context and social background. According to Mills and Gale (2007), positivist conceptualizations fail to highlight sufficiently the complexities of social lived experience. Lived experience is not linear but interactively complex hence it cannot be studied through quantification alone. In the socio-critical sense, the concept of field connotes a social arena in which people interact; manoeuvre and struggle in pursuit of desirable transformation (Bourdieu, 1997). Actions in fields are often restricted by doxa. Doxa is the 'natural attitude'; that is, "utterly taken-for-granted beliefs about the world and existence" and is fundamentally "sustained by shared beliefs and orientations" and is "a generalized sense of "what is done"" in the field (Atkinson, 2011, p. $340)$.

All human actions, including education for rural transformation, take place within social fields. Importantly, fields are arenas of struggle for the acquisition of knowledge, capital, credentials and happiness as indicators of transformation. In rural transformative education, both the educator and people who live in rural communities occupy distinct positions within the field in which struggles or maneuvers take place over specific knowledges or stakes and access to them.

Intellectual distinction, class, prestige and social class in varying degrees often define the stakes education for rural transformation. It is therefore imperative that educators use their knowledge andskills to minimize the struggles between theoretical and research knowledge, and the knowledge that people in rural communities who are the valuable clients bring to the debate of transformation. Contemporary education for rural transformation requires taking a critical stance to embrace and enact genuine equity, value people in rural communities and create opportunity for a more in-depth understanding of their way of life (Deppeler, Moss, \& Agbenyega, 2008). Socio-critical education for rural transformation "takes as one of its central projects an attempt to be discerning and attentive to those places and practices where social agency has been denied and produced" (Giroux, 
2011, p. 3). Therefore, education for rural transformation should not be viewed merely as sites to practise research skill, technique or methods. Without recognizing education for rural transformation as arenas of struggle, we may simply be reducing people in rural communities with our education approaches to cheerful robots (Giroux, 2011, p. 3). Cheerful robots in this sense implies constructing people in rural communities as onlookers who stare in awe as passive recipients of development projects as those needed to be fixed by technocrats or educators. As educators, we are of no benefit to people in rural communities if our approaches continue to embrace instrumental rationality on the surface in which matters of justice, human rights, power and emancipation are silent. This means we need to engage seriously in critical reflexivity when working with people in rural communities.

Practising critical reflexivity in education for rural transformation enjoins educators to move beyond the obvious to interrogate their choices of educational tools and philosophy (theory), approaches and the meanings they assign to them. This means the educators' interaction people in rural communities must not be taken for granted in participatory education for rural transformation. In this way, reflexivity is important to keep the educator on course throughout the education for rural transformative process. According to Bourdieu, reflexivity is "an interrogation of the three types of limitations (social position of field and of the scholastic point of view) that are constitutive of knowledge itself" (Schirato $\&$ Webb, 2003, p. 539). This means educators must become conscious of their class, ethnicity, religion, etc., their position within the field in relation to the people they are educating, and not to abstract education from rural contexts. I argue that the extent to which educators can produce useful knowledge for rural transformation is through the logic of practice and conscious comprehension or reflexivity (Bourdieu, 1990). The discussion of Bourdieu's concepts takes us a step further to analyze the interrelationships between his concepts and education for rural transformation.

\section{Interrelationships of Bourdieu's Concept and Education for Rural Transformation}

Education is integral to Bourdieu's sociological theories, and he argues that educational institutions have remained mechanisms for maintaining and reproducing values within social spaces for each new generation that enters into it instead of it leading to social transformation (Apple, 2004; 2000; Webb et al., 2002). Freire (1970/2000) reiterated that doing education in the traditional sense where educators consider themselves as knowledge givers that transmit knowledge to novice learners is not only colonizing, it is oppressive. It is important to note that "institutions and the manner in which they are organized and controlled are integrally related to the ways in which specific people get access to economic and cultural resources and power" (Apple, 2004, p. vii). In thinking about education for rural transformation, I draw on what Apple (2004) called "critical scrutiny", that is, educators must strive for ways in which to challenge: 
...the whole assemblage of values and actions "outside" of the institution of schooling... [and] must lead to a set of commitments that may be wholly different than those many of us commonsensically accept. It requires a progressive articulation of and commitment to social order that has at its very foundation not the accumulation of goods, profits, and credentials, but the maximization of economic, social, and educational equality. All of these centre on the theory of social justice. (p. 10)

We can see from the above statements that one central feature of education for rural transformation is social justice and equity.

\section{Directions for Culturally Conscientious Education for Rural Transformation}

As we can see, rapid urbanization is displacing people from rural communities as we engage in building new patterns of economic, ecological and social development. It is also creating new dynamics of change for both urban and rural communities. The rapidity of rural-urban migration is both a problem and an opportunity (UNESCO-INRULED, 2012). There are many rural people whose lives have been made worse as a result of rural displacement to make way for types of developments where individuality and affluence are privileged over community. Some people in rural communities who found themselves in urban centres without adequate education, often, have become homeless and destitute. Thus, I argue that rapid urbanization is doing little to help the rural poor. This means a transformational process can be positive and mutually beneficial for urban and rural people, if a coordinated approach for economic and human resource transformation with a regional socioeconomic and ecological transformative perspective can be adopted (UNESCOINRULED, 2012).

Based on the arguments presented in this paper, education for rural transformation calls for educators to critically consider how habitus and capital influence practices in rural communities. Therefore, education for rural transformation must be enacted as a process that allows individuals or group of individuals within rural communities to determine their own future by using cultural logic and resources available to them. Cultural logic implies the epistemological and ontological perspectives that foreground the constitution and sustenance of a particular cultural society. Education for rural transformation must scaffold on reciprocal relationship between people in rural communities and educators, and not on notions of development where individualist perspectives and excessive capital accumulation are favoured against community and environment.

Arguably, the values and traditions of people in rural communities (capital) must be used as guidelines for education (Kanu, 2007).To make education for rural transformation work and respond to the needs of rural people, the cultural knowledge of people in rural communities which is often performance-based, should be used as model for gaining insights into issues that pose threat to their survival. Cultural knowledge is intergenerational, family-oriented, affiliation-oriented and values-based, and draws on 
cultural tools for collective learning and doing for sustainable future living. As illustrated earlier in the introduction section of this paper, an important aspect of education for rural transformation is a focus on group success before individual gains. It is by valuing and placing the habitus and capital of people who live in rural communities at the centre of education for rural transformation that educators can empower them to improve their livelihoods.

\section{Conclusion}

This theoretical paper has examined and analyzed how inclusion or exclusion can manifest for people in rural communities if educators do not pay close attention to the habitus and capital of people in rural communities in the field of education for rural transformation. Some key conclusions that could be drawn from the above analysis include: First, in order to anchor education for rural transformation in the lives of people living in rural communities, we must take their social practices into account, as well as the ways they organize their participation in and across different communities. This form of education is that which is patterned, enabling people to construct meaning in their lives (Barhardt, 2007; Koning, 2010). Bourdieu (1998) argues that habitus is visible through the ways we enact practice. This means, the habitus of educators must help them to enact practices that lead to rural transformation and afford individuals in that culture the opportunity to acquire knowledge and attitudes to improve upon their existing capital.

Second, education for rural transformation must enact knowledge development and transformative processes that afford people in rural communities a way of life fashioned by historical values and present needs in their collective endeavour to prepare for life and to come to terms with their total liberation as people instead of perpetual dependence on others to solve their problems (Gyekye, 2004).As people in rural communities engage in transformative rich education with educators who share their values (habitus), their course of life becomes historically and presently creative, enabling them to evolve bodies of material and intellectual capabilities (capital) and values, which prepare them to better understand and influence their world.

Thirdly, what happens in education for rural transformation must not be taken for granted as given, it is characterized by different habitus, capital and contested fields (Bourdieu, 1998). Education for rural transformation, therefore, need to appreciate changing societal practices, dilemmas and conflicts and incorporate insightful lessons on negotiations, cooperation and approaches that value and guarantee ways of living together. These kinds of considerations have the potential to decolonize knowledge and make education for rural transformation relevant to people living in rural communities (Adjei, 2007).

Finally, education for rural transformation is a socio-ethical doctrine related to social relations as well as values, attitudes and beliefs (habitus) (Bourdieu, 1998; Gyekye, 2004). 
Therefore, the traditional common-sense that can be gleaned from this is that education for rural transformation should focus mainly on teaching the sorts of relationships that should hold between individuals in a society and their environment and the need to take into account the interests of the wider society in performing actions, and "evolving behaviour patterns for individuals in their responses to the needs and welfare of other members of society" (p. 60). If education for rural transformation is not done well then, we cannot say only the past of people living in rural communities that are in ruins (Gross, 1992; Tedla, 1995) but also, their present and their future. Education for rural transformation needs to be taken seriously on the same level as the 'air we breathe' because this is the only way to attach some urgency to rural transformation and rescue the present and future from ruins. An effective education for rural transformation curriculum therefore, needs to take account of habitus and capital of people living in rural communities as well as those of educators to create the kinds of communities in which we expect our rural people to live and thrive.

\section{References}

Adjei, P. (2007). Decolonising knowledge production: The pedagogic relevance of Gandhian Satyagraha to schooling and education in Ghana. Canadian Journal of Education, 30(4), 1046 - 1067.

Adorno, T., \& Horkheimer, M. (1997). Dialectic of enlightenment. London, England: Verso. Agbenyega, J. S. (2014). Beyond alienation: Unpacking the methodological issues in visual research with children. In M. Fleer \& A. Ridgeway (Eds.), Visual methodologies and digital tools for researching with young children: transforming visuality (pp. 153-168). Switzerland: Springer

Asimeng-Boahene, L. (2009). Educational wisdom of African oral literature: African proverbs as vehicles for enhancing critical thinking skills in social studies education. International Journal of Pedagogies and Learning, 5(3), 59-69.

Apple, M. W. (2004). Ideology and curriculum (3rd ed.). London, England: Routledge. Atkinson, W. (2011). From sociological fictions to social fictions: Some Bourdieuian reflections on the concepts of 'institutional habitus' and 'family habitus'. British Journal of Sociology of Education, 32(3), 331-347. doi: 10.1080/01425692.2011.559337 Ball, C. (1989). Towards an enterprising culture: A challenge for education and training. Paris, France: OECD/CERI.

Barhardt, R. (2007). Creating space for indigenous knowledge and continuity: The Alaska native knowledge network. Retrieved from http://www.ankn.uaf.edu/Curriculum/ Articles/Ray-Barnhardt/PBE_ANKN

Bieler, A., \& Morton, A. D. (2004). A critical theory route to hegemony, world order and historical change: Neo-Gramscian perspectives in international relations. Capital and Class, 28, 85-113.

Bourdieu, P. (1990). The logic of practice: Cambridge, England: Polity Press.

Bourdieu, P. (1993). Sociology in question. London, England: Sage. 
Bourdieu, P. (1996). The state nobility. Cambridge, England: Polity Press.

Bourdieu, P. (1997). The forms of capital. In A. Halsey, H. Lauder, P. Brown, \& A. S. Wells (Eds.), Education: Culture, economy and society (pp. 46-58). Oxford, England: Oxford University Press.

Bourdieu, P., \&Passeron, J. C. (1990). Reproduction in education, society and culture (2nd ed.).London, England: Sage.

Bourdieu, P. (1998). Practical reason: On the theory of action. Cambridge, England: Polity. Bourdieu, P. (1999). The weight of the world: Social suffering in contemporary society.

California, CA: Stanford University Press.

Boyer, E. L. (1990). Scholarship reconsidered: Priorities of the professoriate. Princeton, NJ: Princeton University Press.

Deppeler, J. (2010). Professional learning as collaborative inquiry: Working together for impact. In C. Forlin (Ed.), Teacher education for inclusion - Changing paradigms and innovative approaches (pp. 180-188). Oxon, England: Routledge.

Deppeler, J., Moss, J., \& Agbenyega, J. S. (2008).The ethical dilemma of working the visual and digital across space. In J. Moss (Ed.), Researching education visually, digitally and spatially (pp. 209-227). Amsterdam, The Netherlands: Sense Publications.

Ennis, R. H. (1987). A taxonomy of critical thinking Dispositions and abilities. In J. Baron \& R. Sternberg (Eds.), Teaching thinkillg skills: Theory and practice (pp. 9-26. New York: Freeman.

Freire, P. (2000). Pedagogy of the oppressed (M. Ramos, Trans.). New York, NY: Continuum.

Gibson, C., Cahill, A., \& McKay, D. (2010). Rethinking the dynamics of rural transformation: Performing different development pathways in a Philippine municipality. Transactions of the Institute of British Geographers, 35(2), 237-255.

Giroux, H. A. (Ed.). (2011). On critical pedagogy. New York, NY: Continuum.

Gottesman, I. (2010). Sitting in the waiting room: Paulo Freire and the critical turn in the field of education. Educational Studies: A Journal of the American Educational Studies Association, 46(4), 376-399.

Gross, D. (1992). The past in ruins: Tradition and the critique of modernity. Amherst, MA: University of Massachusetts Press.

Gyekye, K. (2004). The unexamined life: Philosophical and the African experience. Accra, Ghana: Ghana Universities Press.

Harker, R., \& May, S. A. (1993). Code and habitus: Comparing the accounts of Bernstein and Bourdieu. British Journal of Sociology of Education, 14(2), 169-178. doi: $10.1080 / 0142569930140204$

Houston, S. (2002). Reflecting on habitus, field and capital: Towards a culturally sensitive social work. Journal of Social Work, 2(2), 149-167.

How, A. (2003).Critical theory. Hampshire, England: Palgrave Macmillan.

Kanter, R. M. (2005). Commitment and community: Communes and utopias in sociological 
38 J. S. Agbenyega

perspective. Cambridge, MA: Harvard University Press.

Kanu, Y. (2007). Tradition and educational reconstruction in Africa in postcolonial and global times: The case for Sierra Leone. African Studies Quarterly, 9(3), 65-84.

Retrieved from http://asq.africa.ufl.edu/files/Kanu-Vol9Issue3.pdf

Kennedy, A., McLoughlin, J., Moore, T., Gavidia-Payne, S., \& Forster, J. (2011). Early childhood intervention project: A revised literature review. Melbourne, Australia: DEECD.

Koning R. (2010). Clifford Geertz's account of culture as a resource for theology. Pacifica, $23,33-45$.

Leonardo, Z. (2004). Critical social theory and transformative knowledge: The functions of criticism in quality education. Educational Researcher, 33(6), 11-18. doi: 10.3102/ 0013189X033006011

Mills, C., \& Gale, T. (2007). Researching social inequalities in education: Towards a Bourdieuian methodology. International Journal of Qualitative Studies in Education, 20(4), 433-447. doi: 10.1080/09518390601176523

Moore, T. G., \& Skinner, A. (2010). An integrated approach to early childhood development. A benevolent society background paper. Sydney, NSW: The Benevolent Society. Retrieved from http://www.rch.org.au/eplibrary/cc/TM BenSoc Project 09.pdf.

Pihama, L. (1993). Tungiate Ururua, kiatupuwhakaritoritotetupu o teharakeke: A critical awareness of parents as first teachers (Unpublished master's thesis). University of Auckland, Auckland. Retrieved from http://www.kaupapamaori.com/action/21/ Ritzer, G. (1996).The McDonaldization of society. Thousand Oaks, CA: Pine Forge Press. Tedla, E. (1995). Sankofa: African thoughts and education. New York, NY: Peter Lang. Tomasello, M. (2009). Culture and cognitive development. In L. S. Liben (Ed.), Current directions in developmental psychology (pp. 207-212). Boston, MA: Pearson.

Seitz, K. (2004). Education and conflict: The role of education in the creation, prevention and resolution of societal crises-Consequences for development cooperation. Bonn, Germany: German Technical Cooperation/Deutsche Gessellschaft fur Technische Zusammenarbeit (GTZ-now GIZ).

Schirato, T., \& Webb, J. (2003).Bourdieu's concept of reflexivity as metaliteracy. Cultural Studies, 17(3-4), 539-553. doi: 10.1080/0950238032000083935

Slee, R. (2011). The irregular school: Exclusion, schooling and inclusive education: Oxon, England: Taylor \& Francis.

UNESCO-INRULED. (2012). Education and training for rural transformation: Skills, jobs, food and green future to combat poverty. Beijing, China: Author.

Wacquant, L. J. D. (1998). Pierre Bourdieu. In R. Stones (Ed.), Key sociological thinkers (pp. 215-229). New York, NY: New York University Press.

Webb, J., Schirato, T., \& Danaher, G. (2002).Understanding Bourdieu. London, England: Sage.

Zibechi, R. (2010). Dispersing power, social movements as anti-state forces. Oakland, CA: AK Press.

Journal of Education and Research, August 2014, Vol. 4, No. 2 